$\mathcal{G}_{\text {https://doi.org/10.3765/sp.10.5 }}^{\text {Semantics \& Pragmatics Volume 10, Article 5: 1-24, } 2017}$

\title{
Deriving the positive polarity behavior of plain disjunction*
}

\author{
Andreea C. Nicolae \\ Leibniz-Zentrum Allgemeine \\ Sprachwissenschaft, Germany
}

Submitted 2016-03-24 / Decision 2016-05-25 / Revision received 2016-10-10 / Decision 2016-10-21 / Revision received 2016-10-27 / Accepted 2016-10-28 / Revision received 2016-10-28 / Early access 2017-03-30 / Published 2019-10-9

\begin{abstract}
The goal of this paper is to show that the positive polarity behavior of plain disjunctions (e.g., French ou 'or') can be analyzed as an interplay between a semantic requirement for obligatory exhaustification and an economy condition which prevents vacuous exhaustification, building on the analysis provided by Spector (2014) to account for the PPI behavior of complex disjunctions (e.g., French soit soit 'either or'). I will argue that plain, but not complex, disjunction allows the pruning of its conjunctive alternative, using as evidence the contrast between these two types of disjunctions when it comes to the optionality of their scalar implicature. I will show that once we assume that exhaustification can take scope over a covert doxastic operator, we can straightforwardly derive the unacceptability of plain disjunction PPIs under negation, even in the absence of a scalar implicature.
\end{abstract}

Keywords: positive polarity, disjunction, exhaustification, scalar implicatures, covert doxastic operator, uncertainty inferences

* I would like to thank Gennaro Chierchia, Luka Crnič, Anamaria Fălăuş, Danny Fox, Andreas Haida, Uli Sauerland and Benjamin Spector for the extensive discussions and encouragement received while working on this paper. This work has been presented and greatly benefited from feedback received at Concordia, MIT and Utrecht, as well as at workshops held in Jerusalem and Göttingen. I am also very grateful for the criticisms and suggestions made by Kjell Johan Sæbø and two S\&P anonymous reviewers. This research was funded by the German Federal Ministry of Research (BMBF Grant Nr. o1UG1411) and the German Research Foundation (DFG Grant SA 925/11-1) within the priority program SPP 1727 XPrag.de. All errors are my own.

(C)2017 Nicolae

This is an open-access article distributed under the terms of a Creative Commons Attribution License (https://creativecommons.org/licenses/by/3.o/). 


\section{Introduction}

The analysis of positive polarity items (PPIs) has been the subject of much debate in recent literature, particularly from the point of view of how it can be unified with the phenomena of implicature calculation more generally. This paper will contribute to this debate by offering an analysis of plain disjunction PPIs (e.g., ou 'or' in French), especially as it relates to the polarity status of its kin, complex disjunction (e.g., soit soit 'either or' in French).

It has long been noted that plain and complex disjunction differ in terms of the strength of their scalar inference, with the inference 'not both' being stronger for complex disjunction, either or, than for plain disjunction, or. Most recently, Spector (2014) has argued that this difference can be attributed to whether or not the scalar alternative of disjunction, conjunction, is obligatorily integrated into meaning, namely, whether disjunction triggers obligatorily exhaustification via the covert alternative-sensitive operator $\mathcal{E} x h$ (cf. Chierchia, Fox \& Spector 2012). Complex disjunctions are also known to exhibit positive polarity behavior cross-linguistically, which Spector argues comes for free once we invoke a notion of economy that takes exhaustification to be licensed only if it leads to a strengthened meaning. In this paper I show that his proposal, as it stands, cannot account for the distribution of plain disjunction PPIs, such as French ou, which I do in Section 4 after introducing the relevant data and background assumptions in Sections 2 and 3. In Section 5 I show that once we supplement his proposal with the assumption that alternatives can be pruned when computing exhaustification (cf. Fox \& Katzir 2011) as well as the claim that uncertainty implicatures can be derived in the grammar (cf. Meyer 2013), the inability of plain disjunction PPIs to receive narrow-scope readings with respect to negation will fall out straightforwardly. This section will also discuss the curious ability of ou to take scope under certain DE operators as well as the fact that it can receive narrow scope in the presence of two DE operators. Lastly, Section 6 concludes and discusses open questions.

\section{Data of interest}

It has been noted that disjunction exhibits polarity sensitivity in some languages but not in others. Specifically, in certain languages disjunction can only receive a wide scope interpretation with respect to negation. The discussion that follows focuses exclusively on English and French, as these two 
Deriving the positive polarity behavior of plain disjunction

languages provide a clear contrast with respect to the available interpretations that arise when disjunction occurs in the presence of negation. Starting with English as the base case, we see that the plain disjunction or can receive both a narrow scope and a wide scope interpretation with respect to negation, given that (1) is ambiguous between (1a) and (1b).

(1) Mary didn't invite Lucy or John for dinner.

a. Mary didn't invite Lucy or she didn't invite John for dinner.

b. Neither Lucy nor John were invited to dinner by Mary.

The French plain disjunction ou, on the other hand, does not illustrate the same ambiguity, with the reading in (2b), where the disjunction has narrow scope, being strongly dispreferred. ${ }^{1}$

(2) Marie n'a pas invité Léa ou Jean à dîner.

'Marie has not invited Léa or Jean for dinner.'

a. Mary didn't invite Lucy or she didn't invite John for dinner.

b. ??Neither Lucy nor John were invited to dinner by Mary.

This inability of disjunction in certain languages to take narrow scope with respect to negation has been dubbed the "anti-licensing" condition, and it constitutes one of three common diagnostics for predicting whether an item is a PPI. As discussed in Szabolcsi 2004, besides the property of "anti-licensing" by negation, another diagnosic for PPI-hood is the ability to be "rescued": if the negation is itself in the scope of a downward entailing operator, then the PPI is claimed to be rescued, i.e., it can receive a narrow scope interpretation with respect to the immediately c-commanding negation. ${ }^{2}$

(3) a. Tout étudiant qui n'a pas pris de cours de maths ou de physique a raté l'examen.

'Every student who neither passed maths nor physics failed the exam.'

b. Si Paul n'avait pas invité Pierre ou Julie à dîner, cela aurait été impoli.

1 Some of the French data is from Spector 2014, and some obtained via personal communication from Isabelle Charnavel, Alexandre Cremers and Jérémy Zehr.

2 There is considerable variation cross-linguistically with respect to which operators can rescue a PPI (see, e.g., Nicolae 2012) but for the purposes of this paper we will deal exclusively with those in (3). 
'If Paul had invited neither Pierre nor Julie for dinner, it would've been rude.'

The goal of this paper is to explain the distributional properties of PPI disjunctions using tools already employed elsewhere in the grammar. The next section offers a very brief overview of the grammatical approach to scalar implicatures, a theory of implicatures that has already been adopted to account for the behavior of other polarity-sensitive elements: NPIs (Chierchia 2004, 2013), epistemic indefinites (Fălăuş 2010) and free-choice items (Fox 2007).

\section{The grammatical approach to scalar implicatures}

I adopt the view that implicatures are derived in the grammar via a mechanism of exhaustification. The idea is that scalar elements activate alternatives and the grammar integrates these alternatives in a systematic way within the meaning of the utterance. Chierchia, Fox \& Spector (2012) (building on work in Krifka 1995, Chierchia 2004, Spector 2006, Fox 2007, among others) argue that scalar implicatures are the result of a syntactic ambiguity resolution in favor of an LF which contains a covert exhaustivity operator $\mathcal{E} x h$, akin to only. Exh negates only innocently excludable alternatives, namely alternative propositions which can be negated without resulting in a meaning that entails another alternative proposition.

(4) $\quad \mathcal{E x h}(p)=p \wedge \forall q \in \operatorname{IE}(p, \mathcal{A l t}(p)): \neg q$.

where: $\operatorname{IE}(p, \mathcal{A l t}(p))=\lambda q \in \mathcal{A l t}(p) . \neg \exists r \in \mathcal{A l t}(p):(p \wedge \neg q) \rightarrow r$

Following Zimmermann 2000, Sauerland 2004, Alonso-Ovalle 2006, Spector 2006 and Fox 2007, we assume that a disjunctive proposition such as (5) is associated with the alternative set in (5a), containing the conjunctive alternative, as well as the individual disjuncts (the so-called domain alternatives). In calculating the result of applying the exhaustification operator, we first need to identify which of the alternatives are innocently excludable. As mentioned above, an alternative is innocently excludable only if its negation can be added to the assertion without resulting in a meaning that entails another alternative. Note that neither domain alternative satisfies this condition as the exclusion of one results in a meaning that entails the other and vice versa. Since neither domain alternative is innocently excludable, the exhaustification proceeds with respect to a subset of the alternative set, namely the set 
Deriving the positive polarity behavior of plain disjunction

containing the conjunctive alternative only. The result of applying $\mathcal{E x h}$ will produce the enriched meaning in (5b):

(5) Mary invited John or Bill.

a. $\quad \mathcal{A l t}($ Mary invited John or Bill $)=\{$ Mary invited John and Bill, Mary invited John, Mary invited Bill\}

b. $\quad$ Exh[Mary invited John or Bill] = Mary invited John or Bill \& Mary didn't invite John and Bill

It is worth noting, however, that a sentence like (5) does not always have the enriched meaning in (5b); depending on the context, the implicature 'Mary didn't invite both John and Bill' may or may not be present. Assuming this grammatical approach to scalar implicatures, there are a few ways to think about the optionality of implicatures. One option is to take exhaustification to be an obligatory operation across the board and appeal to a notion of alternative pruning in order to derive non-enriched meanings. Under this approach the difference between the inclusive (non-enriched) and exclusive (enriched) use of disjunction would be the result of what alternative set $\mathcal{E} x h$ makes reference to: for the inclusive reading the alternative set would be empty, whereas for the exclusive reading the alternative set would be as in (5a). ${ }^{3}$ Another option is to assume that the exhaustification operator is itself optional. Under this approach, a sentence like (5) can be said to be ambiguous between the two LFs in (6).

(6) Mary invited John or Bill.

a. Mary invited John or Bill

inclusive

b. Exh[Mary invited John or Bill]

exclusive

For the purposes of this paper I will couch the analysis in terms of a hybrid approach to exhaustification, wherein both alternative pruning and optionality of exhaustification can be employed, although it is worth noting that assuming exhaustification is optional is akin to assuming that all alternatives are pruned.

3 The prejacent of $\mathcal{E x h}$ is itself an alternative but for presentational purposes I will not include it in the alternative set. 
Nicolae

\section{Plain versus complex disjunctions}

Most languages have more than one way of conveying disjunction. For example, in English we find or and either or, in French ou, ou ou and soit soit, in Romanian sau, ori, ori ori, fie fie, in Hungarian vagy, vagy vagy and akár akár and in German we encounter oder and entweder oder. One of the main differences between these ways of conveying disjunction within a language boils down to whether the disjunction is interpreted inclusively or exclusively in positive contexts. ${ }^{4}$ The exclusive interpretation comes about whenever the use of a disjunction gives rise to the inference that it cannot be the case that both disjuncts are true. For example, in English both or and either or can give rise to the inference 'not both'.

(7) a. Mary will visit John or Bill. $\sim$ Mary won't visit both.

b. Mary will visit either John or Bill. $\sim$ Mary won't visit both.

The difference between these two disjunctions comes when we try to cancel this inference. Whereas (8a) can be continued with 'possibly both', (8b) cannot, at least not as easily, which has been taken to suggest that either or is the natural language counterpart of the logical exclusive disjunction, while or is the natural language counterpart of the logical inclusive disjunction. ${ }^{5}$

a. Mary will visit John or Bill. ... possibly both

b. Mary will visit either John or Bill. ..." possibly both

The same contrast is observed cross-linguistically. In French, for example, the difference between the disjunctions ou and soit soit is parallel to the difference noted above for English: soit soit gives rise to the exclusivity inference more robustly than $o u$, given that a continuation which contradicts the scalar inference is significantly less natural if the complex disjunction soit soit is used.

(9) a. Marie ira au cinéma lundi ou mardi.

'Marie will go to the movies on Monday or Tuesday.'

b. Absolument! Et elle ira même à la fois lundi ET mardi.

'Absolutely! She will even go both days.'

4 Nonetheless, in the languages that make a three and even a four-way distinction, it remains to be understood what other levels of variation there are.

5 Nicolae \& Sauerland (2016) provide experimental evidence in support of this claim. 
Deriving the positive polarity behavior of plain disjunction

(10) a. Marie ira au cinéma soit lundi soit mardi.

'Marie will go to the movies either on Monday or Tuesday.'

b. \#Absolument! Et elle ira même à la fois lundi ET mardi.

'Absolutely! She will even go both days.'

\subsection{Spector's (2014) account of complex disjunction PPIs}

Spector (2014) argues that cross-linguistically, complex disjunctions also exhibit PPI-like behavior. ${ }^{6}$ For example, French soit soit cannot receive a narrow scope interpretation with respect to a c-commanding negation, (11), but it can if the negation is further embedded under a downward-entailing operator, (12).

(11) Pierre ne parle pas soit allemand soit anglais. 'Pierre doesn't speak soit German soit English.'

a. Pierre doesn't speak German, or he doesn't speak English.

b. *Pierre doesn't speak either German or English.

(12) Je n'emmène jamais Marie au cinéma sans qu'elle ait demandé la permission soit à son père soit à sa mère.

'I never bring Marie to the movies without her having asked permission from her father or from her mother.'

Spector claims that these two distributional restrictions observed with complex disjunctions, obligatory scalar implicatures and restriction to upward entailing environments, should be seen as the result of the same underlying mechanism. In particular, he argues that complex disjunctions should be analyzed as scalar elements that obligatorily trigger exhaustification. As already discussed, scalar implicatures are the result of applying the $\mathcal{E x h}$ operator, as repeated below:
a. $\mathcal{E} x h[p \vee q]=(p \vee q) \wedge \neg(p \wedge q)$
b. $\quad \mathcal{E x h}[$ Mary will visit John or Bill] = Mary will visit John or Bill \& Mary won't visit John and Bill

Why is the scalar implicature 'not both' associated with soit soit and either or stronger than that of ou and or, respectively? The claim is that unlike plain disjunction, which is ambiguous between the two LFs in (14), the complex

6 Except for English either or which is not a PPI, as pointed out by Spector himself. I will return to a discussion of either or in the concluding remarks of the paper. 
disjunction is unambiguously interpreted with an $\mathcal{E x h}$ operator, that is, only the LF in (14b) is available.
a. $[p \vee q]$
${ }^{r}$ ou, ${ }^{x}$ soit soit
b. $\mathcal{E x h}[p \vee q]$
${ }^{\vee}$ ou, ${ }^{\vee}$ soit soit

This straightforwardly accounts for the obligatory presence of an implicature with complex but not plain disjunctions. In order to account for the PPI behavior of complex disjunctions, Spector has to furthermore assume that the application of $\mathcal{E x h}$ is constrained by a pragmatic economy condition which dictates that the contribution of $\mathcal{E x h}$ must give rise to strengthening (cf. Fox \& Spector 2018, among others).

(15) An occurrence of $\mathcal{E x h}$ in a sentence $S$ is not licensed if eliminating this occurrence leads to a sentence $S^{\prime}$ which entails or is equivalent to $S$.

If soit soit is analyzed as a disjunction (with conjunction as its alternative) which triggers obligatory exhaustification, the PPI-like behavior of this element comes out straightforwardly. Since disjunction is weaker than conjunction only in upward entailing environments, only in these environments does the contribution of $\mathcal{E x h}$ lead to strengthening, (16) versus (17), hence the restriction of soit soit to upward entailing environments.

$\mathcal{E x h}[p \vee q]$

a. $\quad \mathcal{A l t}(p \vee q)=\{p, q, p \wedge q\}$

b. $\quad \mathcal{E x h}[p \vee q]=(p \vee q) \wedge \neg(p \wedge q)$

(17) $\quad \mathcal{E x h}[\neg(p \vee q)]$

a. $\quad \operatorname{Alt}(\neg(p \vee q))=\{\neg p, \neg q, \neg(p \wedge q)\}$

b. $\quad \mathcal{E x h}[\neg(p \vee q)]=\neg(p \vee q)$

\subsection{The problem of plain disjunction PPIs}

To recapitulate, plain and complex disjunctions are distinguished by the strength of the scalar implicature not both: in the case of plain disjunction the implicature is easier to cancel than in the case of complex disjunction. Spector (2014) argues that the strength of the implicature and the positive polarity status of complex disjunctions have the same source, namely an obligatory association with an exhaustification operator whose insertion is 
Deriving the positive polarity behavior of plain disjunction

subject to the economy condition in (15). In other words, being a PPI is tied to the presence of a scalar implicature. While this analysis works well for complex disjunctions, it leaves wide open the question of how to analyze plain disjunction PPIs like French ou, given that plain disjunctions are only optionally associated with scalara implicatures. The goal going forward is to argue that, more generally, PPIs are elements which are lexically marked as triggering obligatory exhaustification. I choose to encode obligatory exhaustification as a lexical requirement (similarly to the approach taken in Chierchia 2013 to deal with NPIs). As it is generally the case with polarity phenomena, it is difficult to explain why certain elements exhibit polarity sensitivity in some languages but not in others, so for the purpose of this paper I will simply have to stipulate that certain disjunctions lexically encode the need for obligatory exhaustification whereas others do not.

The first step in the analysis will be to render the scalar implicature optional in the case of plain disjunctions. In this spirit, I follow previous authors (Fox \& Katzir 2011, Crnič, Chemla \& Fox 2015) who have argued that alternatives can be pruned, namely that exhaustification can proceed with respect to a subset of the set of innocently excludable alternatives. I will adopt this assumption and propose that plain disjunction may prune the scalar alternative from its alternative set, whereas complex disjunction may not. ${ }^{7}$

In other words, a plain disjunction can associate with either of the alternative sets in (18), whereas a complex disjunction is restricted to the full alternative set in (18a). The argument for restricting complex disjunctions to the set in (18a) comes from the fact that they appear to obligatorily give rise to a scalar implicature (cf. Spector 2014, Nicolae \& Sauerland 2016). From here on out I will annotate these different alternative sets as $\mathcal{A} l t_{S}$ and $\mathcal{A} l t_{D}$ respectively. I will furthermore subscript the exhaustification operator with $S$ (for scalar) or D (for domain) to indicate which alternative set the operator associates with.

$$
\begin{aligned}
& \text { a. } \mathcal{A l t}_{S}(p \vee q)=\{p, q, p \wedge q\} \\
& \text { b. } \mathcal{A l t}_{D}(p \vee q)=\{p, q\}
\end{aligned}
$$

7 As already discussed in Fox \& Katzir 2011 and Ivlieva 2012, pruning of alternatives must be constrained. For example, pruning the conjunctive alternative should not be allowed if recursive exhaustification is employed, for the end result would be a conjunctive meaning. I will adopt a constraint on pruning which requires the result of exhaustification with respect to a pruned set of alternatives to give rise to a meaning that could not have been expressed by a (stronger) alternative obtained via lexical replacement. 
The claim will be that plain disjunction PPIs (French ou), like complex disjunction PPIs (French soit soit), and unlike plain disjunction non-PPIs (English or) trigger obligatory exhaustification, an operation which is governed by the economy condition ruling out vacuous instances of $\mathcal{E x h}$ (cf. (15)). The difference between the two types of disjunction PPIs will be that plain disjunction PPIs trigger exhaustification with respect to a (possibly) different set of alternatives, namely the one in (18b). Let's consider the predictions of such an account. Under negation, the domain alternatives will be as in (19a). Since the alternatives are entailed by the assertion, the exhaustification will be vacuous, as in (19b). ${ }^{8}$

$$
\begin{aligned}
& \mathcal{E x} h_{D}[\neg(p \vee q)] \\
& \text { a. } \mathcal{A l t}_{D}(\neg(p \vee q))=\{\neg p, \neg q\} \\
& \text { b. } \quad \mathcal{E x h}_{D}[\neg(p \vee q)]=\neg(p \vee q)
\end{aligned}
$$

So far this is a welcome result. The economy condition on $\mathcal{E x h}$ rules it out whenever its contribution does not lead to strengthening. Since ou triggers obligatory exhaustification, the vacuity of $\mathcal{E x h}$ under negation delivers the unacceptability of ou under negation. On the other hand, since English or doesn't obligatorily trigger exhaustification, no problem will arise in a DE environment since an LF without $\mathcal{E} x h$ is acceptable.

Unfortunately, a problem arises once we turn to UE contexts. Recall that we are assuming exhaustification takes place only with respect to innocently excludable alternatives. Since the alternatives in (20a) are not innocently excludable, the exhaustification of the assertion with respect to this set will be vacuous, as in (20b):

$$
\begin{aligned}
& \mathcal{E x} h_{D}[p \vee q] \\
& \text { a. } \mathcal{A l t}_{D}(p \vee q)=\{p, q\} \\
& \text { b. } \mathcal{E x}_{D}[p \vee q]=p \vee q
\end{aligned}
$$

What this account predicts then is that ou should also be ruled out in UE cases given that here too the result of exhaustification is vacuous. This is obviously a wrong prediction and a solution needs to be found. A possible way of avoiding the vacuity in (20b) would be by exhaustifying with respect to $\mathcal{A} l t_{S}$, as in (21):

8 Another option of course would be to exhaustify below the negation, $\neg\left[\mathcal{E} x h_{D}[p \vee q]\right]$. The domain alternatives in this configuration are not innocently excludable, rendering the exhaustification vacuous. 
Deriving the positive polarity behavior of plain disjunction

(21) $\mathcal{E} h_{S}[p \vee q]$

a. $\mathcal{A l t}_{S}(p \vee q)=\{p, q, p \wedge q\}$

b. $\operatorname{Exh}_{S}[p \vee q]=(p \vee q) \wedge \neg(p \wedge q)$

The issue with such an approach is that it would mean that in UE contexts the plain disjunction would always give rise to a scalar implicature, given the necessity of including the scalar alternative in order to avoid vacuous exhaustification. That is clearly not the case given the facts outlined earlier when describing the difference between plain and complex disjunction, namely that ou does not obligatorily trigger a scalar implicature. Employing this mechanism would essentially obfuscate the difference between plain and complex disjunction, making a wrong empirical prediction.

The problem of plain disjunction PPIs thus remains. With the tools available thus far, we have no way of deriving the PPI behavior of plain disjunctions simply by appealing to obligatory exhaustification.

\section{A solution to the problem of plain disjunction PPIs}

We saw in the previous section that the ban on vacuous exhaustification makes the wrong prediction when it comes to the distribution of plain disjunction PPIs in UE contexts. In this section I will argue that this problem will not arise if we adopt the proposal in Meyer 2013 which takes uncertainty implicatures, such as the one in (22), normally thought of as arising via pragmatic principles (e.g., via Grice's Cooperative Principle), to also be derived in the grammar, similarly to scalar implicatures.

(22) Mary invited John or Paul. $\leadsto$ But I don't know which.

Meyer's claim is that assertively used sentences contain a covert doxastic operator which is adjoined at the matrix level at LF (cf. also Kratzer \& Shimoyama 2002, Chierchia 2006 and Alonso-Ovalle \& Menéndez-Benito 2010 for similarly minded proposals). She calls this operator $K$ (following Gazdar (1979)) and gives it the semantics in (23). I represent this operator as a necessity modal throughout the remainder of the text.

(23) $\llbracket \square_{x} p \rrbracket=\lambda w \cdot \forall w^{\prime} \in \operatorname{Dox}(x)(w): p\left(w^{\prime}\right)$

$w^{\prime} \in \operatorname{Dox}(x)(w)$ iff given the beliefs of $x$ in $w$, w' could be the actual world. 
By bringing this operator into the grammar we can derive the uncertainty implicatures of disjunction similarly to how we derive its scalar implicature, via the application of an exhaustification operator. This implicature is obtained by having the exhaustifier take scope over the doxastic operator, as in (24):

(24) $\mathcal{E} x h_{D}[\square[p \vee q]]$

a. $\mathcal{A l t}_{D}(\square[p \vee q])=\{\square p, \square q\}$

b. $\mathcal{E} x h_{D}[\square[p \vee q]]=\square(p \vee q) \wedge \neg \square p \wedge \neg \square q$

Exhaustifying with respect to this set of alternatives will deliver uncertainty implicatures about the two domain alternatives, given that the domain alternatives are now innocently excludable. For a sentence such as 'Mary visited John or Bill', the enriched meaning in (24b) will amount to 'I am certain that Mary visited one of the two, but it's possible she didn't visit John and it's possible she didn't visit Bill', hence the uncertainty with respect to the status of the individual disjuncts.

Adopting this way of deriving uncertainty implicatures allows for a uniform approach to implicatures, both scalar and uncertainty. Most importantly for our purposes, however, it straightforwardly derives the acceptability of elements triggering obligatory (and thus strengthening) exhaustification in UE cases. Notice that the enriched meaning in (24b) is stronger than the nonenriched meaning. In other words, the exhaustification is no longer vacuous, rendering the PPI disjunction ou acceptable in UE contexts.

Before concluding this section it is worth checking that under negation the presence of the doxastic operator does not lead to any (undesired) strengthening. The result of exhaustification in (25) will be vacuous given that the sister of $\mathcal{E} x h_{D}$, which is equivalent to $\square \neg p \wedge \square \neg q$, by epistemic logic, entails each of the alternatives.

$$
\mathcal{E x} h_{D}[\square \neg[p \vee q]]
$$

a. $\mathcal{A l t}_{D}(\square \neg[p \vee q])=\{\square \neg p, \square \neg q\}$

b. $\mathcal{E} h_{D}[\square \neg[p \vee q]]=\square \neg(p \vee q)$

We have successfully shown why plain disjunction PPIs are unacceptable under negation but acceptable in UE environments if we analyze them as elements that trigger obligatory exhaustification and allow pruning of the scalar alternative. 
Deriving the positive polarity behavior of plain disjunction

\subsection{Re-assessing complex disjunction}

Taking uncertainty implicatures to be derived in the semantics, as Meyer (2013) suggests, requires us to re-evaluate the case of complex disjunction. Whereas plain and complex disjunctions differ with respect to the availability of their scalar implicature, they do not exhibit the same variability when we turn to the uncertainty implicature. Both types of disjunction give rise to this implicature just as robustly:

$$
\text { Mary visited (either) John or Bill. } \sim \text { But I don't know which. }
$$

Since the source of the uncertainty implicature is the interaction between the doxastic operator and the domain alternatives, we must check what happens when exhaustification occurs with respect to both scalar and domain alternatives in the presence of the doxastic operator. In particular, we need to ensure that the scalar implicature is still derived. Since complex disjunction does not allow its scalar alternative to be pruned, we need to check the result of exhaustification via $\mathcal{E x} h_{S}$, as in (27):

(27) $\quad \mathcal{E x} h_{S}[\square[p \vee q]]$

$$
\begin{array}{ll}
\text { a. } & \mathcal{A} l t_{S}(\square[p \vee q])=\{\square p, \square q, \square[p \wedge q]\} \\
\text { b. } \quad \mathcal{E x h}_{S}[\square[p \vee q]] & =\square(p \vee q) \wedge \neg \square p \wedge \neg \square q \wedge \neg \square(p \wedge q)
\end{array}
$$

Observe that while the uncertainty implicature is still derived, the scalar implicature is weakened (last conjunct), deriving instead something much weaker, namely that it's possible not both. This is not ideal since the difference between plain and complex disjunction is no longer derived.

There is, however, another possible LF, one where the exhaustification is embedded, as in (28). Appealing to embedded exhaustification allows us to derive the stronger scalar implicature, namely that it is necessarily not the case that both are true. It's crucial of course that we also employ matrix exhautification or else the uncertainty implicature would not be derived.

$$
\begin{aligned}
& \mathcal{E x} h_{S}\left[\square\left[\mathcal{E x} h_{S}[p \vee q]\right]\right] \\
& \text { a. } \mathcal{A l t}_{S}(p \vee q)=\{p, q, p \wedge q\} \\
& \text { b. } \quad \mathcal{E x} h_{S}[p \vee q]=(p \vee q) \wedge \neg(p \wedge q) \\
& \text { c. } \mathcal{A} \text { Alt } t_{S}\left(\square \mathcal{E} x h_{S}[p \vee q]\right)=\left\{\square \mathcal{E x} h_{S} p, \square \mathcal{E x} h_{S} q, \square \mathcal{E x} h_{S}[p \wedge q]\right\} \\
& \text { d. } \mathcal{E} x h_{S} \square \mathcal{E} x h_{S}[p \vee q] \\
& =\{\square[p \wedge \neg q], \square[q \wedge \neg p], \square[p \wedge q]\} \\
& =\square[p \vee q] \wedge \square \neg[p \wedge q] \wedge \neg \square[p \wedge \neg q] \wedge \neg \square[q \wedge \neg p]
\end{aligned}
$$


If we think of (27) and (28) as two competing LFs, we can invoke the Strongest Meaning Hypothesis (Dalrymple et al. 1998) and end up with (28) as the preferred reading, as desired. This might turn out to be good for another reason: complex disjunction can, sometimes, lack the exclusivity inference, and instead of attributing this behavior to the optionality of scalar exhaustification (which would go against the proposal in Spector 2014), we can instead claim that the LF in (27) is employed. ${ }^{9}$

This section has shown that adopting an account of uncertainty implicatures that takes them to be derived in the grammar allows us to make the same predictions as before, namely that complex disjunctions give rise to a scalar implicature.

\subsection{PPIs without uncertainty implicatures?}

A prediction made by this account is that non-PPI disjunctions, which do not trigger obligatory exhaustification, should allow for continuations that contradict the uncertainty inference. This prediction appears to be correct, given the felicity of the discourse below.

(29) Mary talked with John or Paul. In fact, she talked with both.

If I'm certain that Mary talked with both John and Paul, then it can't be possible that she didn't talk with John, nor can it be possible that she didn't talk with Paul, i.e., the uncertainty inference must be false. We saw above that exhaustification with respect to the domain alternatives will give rise to a strengthened meaning only in the presence of a speaker-oriented doxastic operator. By relying on the presence of this operator to derive a strengthened meaning upon exhaustification, we make the prediction that a plain disjunction PPI will only ever be able to receive an interpretation in an UE context if it gives rise to an uncertainty inference. This is a wrong

9 Note that the LF in (27) is also a possible interpretation for plain disjunctions. One could in fact conceive of framing the difference between plain and complex disjunctions in terms of matrix versus embedded exhaustification, i.e., (27) versus (28), respectively. If this approach were adopted, however, more would have to be said about the need for embedded exhaustification with complex disjunction. One avenue to pursue would be to argue that the disjuncts in complex disjunction are interpreted exhaustively, support for which we can draw from the fact that such disjunctions are usually associated with prosodic focus on the disjuncts. The LF for complex disjunctions would thus be $\mathcal{E} x h_{S}\left[\square\left[\mathcal{E x} h_{D} p \vee \mathcal{E x} h_{D} q\right]\right]$ rather than (28), which gives rise to the same meaning as in (28d). 
Deriving the positive polarity behavior of plain disjunction

prediction given that the French equivalent of (29), given in (30), is perfectly felicitous.

(30) Marie a parlé à Jean ou Paul. En fait, elle a parlé aux deux.

The continuation 'in fact both', $\square(p \wedge q)$, is incompatible with the uncertainty implicature obtained by the application of the exhaustification operator, provided in (31). So what gets us into trouble with the continuation is precisely what allowed a PPI disjunction to receive an interpretation in UE cases (under the analysis pursued here), namely the strengthening via the uncertainty implicature.

$$
\neg \square p \wedge \neg \square q
$$

What we need then is to derive a strengthened meaning of the disjunction that will be compatible with the continuation in (29). I argue that invoking both embedded and matrix exhaustification with respect to the domain alternatives will yield a meaning compatible with a situation in which both are true.

$$
\begin{aligned}
& \mathcal{E} x h_{D}\left[\square\left[\mathcal{E} x h_{D}[p \vee q]\right]\right] \\
& \text { a. } \mathcal{A} t_{D}(p \vee q)=\{p, q\} \\
& \text { b. } \mathcal{E} h_{D}[p \vee q]=p \vee q \\
& \text { c. } \mathcal{A l t}_{D}\left(\square\left[\mathcal{E} x h_{D}[p \vee q]\right]\right)=\left\{\square \mathcal{E} x h_{D} p, \square \mathcal{E} x h_{D} q\right\} \\
& =\{\square(p \wedge \neg q), \square(q \wedge \neg p)\} \\
& \text { d. } \mathcal{E} x h_{D}\left[\square\left[\mathcal{E x h} h_{D}[p \vee q]\right]\right]=\square(p \vee q) \wedge \neg \square(p \wedge \neg q) \wedge \neg \square(q \wedge \neg p) \\
& \equiv \diamond p \wedge \diamond q
\end{aligned}
$$

The equivalence in (32d) holds because if it's true that Mary necessarily talked with John or Paul but that she didn't necessarily talk only with John, then it follows that it's possible that she talked with Paul, and vice versa. This recursively enriched meaning is now compatible with a situation in which both $p$ and $q$ must be true..$^{10}$

In summary, we can now understand how it is possible for an unembedded plain disjunction that exhibits PPI behavior to lack both a scalar and

10 This same approach is independently adopted by Crnič, Chemla \& Fox (2015) to account for the observation that sentences with disjunction in the scope of a universal quantifier, Every $A$ is $P$ or $Q$ tend to give rise to distributive inferences that each of the disjuncts holds of at least one individual in the domain of the quantifier, Some $A$ is $P$ \& Some $A$ is $Q$ in the absence of plain negated inferences, Not every $A$ is $P \&$ Not every $A$ is $Q$. 
an uncertainty implicature, and yet still count as strengthened for the purposes of satisfying the economy condition on non-vacuous exhaustification. Whereas in the case of English or we might have dealt with the acceptability of this continuation by simply stating that the exhaustification is not obligatory, in the case of the French ou, a PPI, such an approach is not possible since the disjunction triggers obligatory exhaustification. Suspending exhaustification in this case should not be an option for then we would expect exhaustification to also be suspendable under negation, therefore no longer deriving the unacceptability of disjunction in such contexts.

\subsection{Overgeneration issues}

The analysis as presented thus far predicts that ou should be unacceptable under any downward entailing operator. This is a wrong prediction, as evidenced by the data in (33) where ou can receive a narrow scope interpretation with respect to DE operators such as 'few', 'less than ten', as well as in the antecedent of conditionals and the restrictor of universals.

(33) a. Peu de/Moins de dix étudiants parlent espagnol ou italien. 'Few/Less than ten students speak Spanish or Italian.'

b. Si Marie a pris un cours de maths ou de physique ce semestre, elle réussira l'examen.

'If Mary took math or physics this semester, she'll pass the exam.'

c. Tout étudiant qui a pris un cours de maths ou de physique réussira l'examen.

'Every student who took math or physics passed the exam.'

This is reminiscent of the behavior of strong NPIs like English 'until' and 'in weeks' which, unlike weak NPIs such as 'any' and 'ever', are acceptable under negation but not in the environments above (Homer 2009, Gajewski 2011, Chierchia 2013).

(34) a. No students have attended this course in weeks.

b. "Few/less than ten students have attended this course in weeks.

c. "If Mary has attended this course in weeks, she should inform us.

d. "Every student who has attended this course in weeks will pass.

The claim put forth by Gajewski (2011) to account for this contrast is that strong, but not weak, NPIs see not only the truth-conditional meaning but 
Deriving the positive polarity behavior of plain disjunction

also the non-truth-conditional meaning of their licensors; this includes whatever implicatures and/or presuppositions the licensor may give rise to. For example, 'few' in (34b) gives rise to the implicature that some students have completed their homework. While 'few' on its own creates a DE environment, when conjoined with its implicature, the overall monotonicity is no longer downward-entailing, but rather non-monotonic. Since the mechanism of NPI licensing requires them to occur in a DE environment, the unacceptability of strong NPIs under operators like 'few' falls out immediately (see Chierchia 2013 for the details of the account). The same can be argued for 'less than $n$, while in the case of the antecedent of conditionals and the restrictor of universals, what disrupts the downward-entailing monotonicity is the presupposition associated with the conditional and the quantifier, respectively.

I will argue that the acceptability of ou in (33) can be accounted for via the same logic. In particular, I will propose that PPIs like ou look at both the truth-conditional and non-truth-conditional meaning of their licensor, making them the counterparts of strong NPIs within the PPI domain. ${ }^{11}$ In the remainder of the section I will demonstrate how this works by focusing on the felicity of PPI disjunctions in the restrictor of universal quantifiers.

To reiterate, the disjunction in (33c) is interpreted in the restrictor of the universal. If we only looked at the truth-conditional meaning when calculating the result of applying $\mathcal{E x h}$ at the matrix level in (33c) we would expect only a wide-scope interpretation of ou, given that the restrictor of universals creates a DE environment. In order to account for the acceptability of PPIs in the restrictor of the universal, I will make the aforementioned assumption that presuppositions can enter into the calculation of exhaustification. The crucial observation is that the restrictor of a universal quantifier is Strawson-DE (cf. von Fintel 1999), due to the fact that universal quantifiers contribute a presupposition of existence, provided in (35).

(35) Every student who took math or physics passed the exam. defined if: Some student(s) took math or physics.

I will argue that the exhaustification occurs with respect to the conjunction of the assertion and the presupposition, as in (36). Given the alternatives in

11 This approach is supported by an observation made by van der Wouden (1997) that crosslinguistically, PPIs exhibit the same variation familiar from the domain of NPIs. For example, just like ou is the PPI counterpart of strong NPIs, the Dutch allerminst 'not in the least' is a PPI that is unacceptable under operators like 'few' and 'less than $n$ ', namely the counterpart of weak NPIs like 'any' and 'ever'. 
(36a), the result of exhaustification is the enriched meaning in (36b), with the inference that it's possible that nobody took math and it's possible that nobody took physics.

$\mathcal{E x h}_{D}[\square \forall x[[p \vee q](x) \rightarrow r(x)] \wedge \square \exists x[[p \vee q](x)]]$

a. $\mathcal{A l t}_{D}(\square \forall x[[p \vee q](x) \rightarrow r(x)] \wedge \square \exists x[[p \vee q](x)])$

$$
=\left\{\begin{array}{l}
\square \forall x[p(x) \rightarrow r(x)] \wedge \square \exists x[p(x)], \\
\square \forall x[q(x) \rightarrow r(x)] \wedge \square \exists x[q(x)]
\end{array}\right\}
$$

b. $\mathcal{E} x h_{D}[\square \forall x[[p \vee q](x) \rightarrow r(x)] \wedge \square \exists x[[p \vee q](x)]]$

$$
\begin{aligned}
& =\left(\begin{array}{c}
\square \forall x[[p \vee q](x) \rightarrow r(x)] \wedge \square \exists x[[p \vee q](x)] \\
\wedge \neg \square \exists x[p(x)] \wedge \neg \square \exists x[q(x)]
\end{array}\right) \\
& =\left(\begin{array}{c}
\square \forall x[[p \vee q](x) \rightarrow r(x)] \wedge \square \exists x[[p \vee q](x)] \\
\wedge \diamond \neg \exists x[p(x)] \wedge \diamond \neg \exists x[q(x)]
\end{array}\right)
\end{aligned}
$$

What (36) shows is that exhaustification of the domain alternatives is nonvacuous as soon as the presupposition is taken into account, meaning that ou is correctly predicted to survive in the restrictor of universals. A similar argument can be made for the antecedent of conditionals which carry the presupposition that the restrictor is a possibility. As for quantifiers like 'few' and 'less than $n$ ', the implicatures these operators give rise to play the same role as the presupposition of 'every' did above, namely they create a non-monotonic environment whereby the exhaustification triggered by the PPI is non-vacuous.

\subsection{Rescuing by a second negation}

Recall that (37) is unambiguously interpreted with disjunction taking wide scope over negation.

(37) Marie n'a pas pris un cours de maths ou de physique ce semestre. 'Mary either didn't take math or she didn't take physics this semester.'

The observation is that if we further embed (37) in a DE context as in (38b), the disjunction can be interpreted in the scope of negation. For example, beyond the wide scope reading of disjunction, (38a) also has the possible reading that the students who took neither math nor physics failed the exam. 
Deriving the positive polarity behavior of plain disjunction

(38) a. Tout étudiant qui n'a pas pris de cours de maths ou de physique a raté l'examen.

'Every student who took neither math onr physics failed the exam.'

b. Si Marie n'a pas pris un cours de maths ou de physique, elle a raté l'examen.

'If Mary took neither math nor physics, she failed the exam.'

Being embedded under two DE operators is equivalent to being in a positive environment for the purposes of exhaustification: (i) the alternatives are stronger than the assertion, and (ii) the result of exhaustification is not vacuous. Below I illustrate this for the case of a negated disjunction in the restrictor of a universal:

$\mathcal{E} x h_{D}[\square \forall x[\neg[p \vee q](x) \rightarrow r(x)] \wedge \square \exists x[\neg[p \vee q](x)]]$

a. $\mathcal{A l t}_{D}(\square \forall x[\neg[p \vee q](x) \rightarrow r(x)] \wedge \square \exists x[\neg[p \vee q](x)])$ $=\left\{\begin{array}{l}\square \forall x[\neg p(x) \rightarrow r(x)] \wedge \square \exists x[\neg p(x)], \\ \square \forall x[\neg q(x) \rightarrow r(x)] \wedge \square \exists x[\neg q(x)]\end{array}\right\}$

b. $\mathcal{E} x h_{D}[\square \forall x[\neg[p \vee q](x) \rightarrow r(x)] \wedge \square \exists x[\neg[p \vee q](x)]]$

$$
=\left(\begin{array}{r}
\square \forall x[\neg[p \vee q](x) \rightarrow r(x)] \wedge \square \exists x[\neg[p \vee q](x)] \\
\wedge \neg \square \forall x[\neg p(x) \rightarrow r(x)] \wedge \neg \square \forall x[\neg q(x) \rightarrow r(x)]
\end{array}\right)
$$

The result of exhaustification is the inference that it's not necessarily the case that every student who didn't take math failed the exam, and similarly, that it's not necessarily the case that every student who didn't take physics failed the exam.

\section{Overview and outlook}

In this paper I argued that the PPI behavior of plain disjunction should be analyzed as an interplay between a semantic requirement for obligatory exhaustification and an economy condition which prevents vacuous exhaustification, building on the analysis provided by Spector (2014) to account for the PPI behavior of complex disjunctions cross-linguistically. I showed that

once this system is adopted, coupled with a condition on alternative pruning and the claim that exhaustification can take scope over a covert doxastic operator, we can straightforwardly derive the restricted distribution of plain disjunction PPIs. Specifically, I argued that plain, but not complex, disjunction 
allows the pruning of its conjunctive alternative, using as evidence the contrast between these two types of disjunction when it comes to the optionality of their scalar implicature. This analysis was shown to derive the inability of PPIs to scope under a local negation, their ability to be rescued by a second DE operator, as well as the fact that plain disjunction PPIs can survive in the absence of uncertainty implicatures.

What was not discussed in this paper was the fact that ou can take narrow scope with respect to an extra-clausal negation, as shown in (40).

(40) Paul ne pense pas que Marie ait invité Pierre ou Julie à dîner. 'Paul doesn't think that Marie invited Pierre or Julie for dinner.'

a. Paul doesn't think that Marie invited Pierre or he doesn't think that Marie invited Julie to dinner. or $>$ not

b. Paul doesn't think that Marie invited Pierre and he doesn't think that Marie invited Julie to dinner. not $>$ or

The analysis, as laid out in this paper, predicts ou to be unacceptable under negation, regardless of its locality. There are, as I see, a couple of ways to tackle this problem. One possibility would be to invoke two levels of recursive exhaustification, namely below and above the negation; doing so would deliver the narrow scope reading of the disjunction, while also employing exhaustification (cf. Nicolae 2016 for the details of such an analysis). The fact that we are dealing with a clause boundary between the negation and the disjunction might be the clue to understanding why the application of the exhaustification operator can be said to be non-vacuous when the negation is extra-clausal, but not when it is local to the disjunction. There are, however, issues with this approach, pertaining to alternative selection as well as the strengthening condition on exhaustification, and space limitations prevent me from discussing this further. Yet another possibility for dealing with this contrast would be to look at how the embedding predicate interacts with the c-commanding negation and whether this interaction leads to any inferences that may satisfy the non-vacuity condition on the exhaustifying operator. I hope to tackle these possibilities on another occasion.

Any discussion of positive polarity would not be complete without at least a mention of how it can be integrated within the larger polarity system. Presently, the proposal offered here to account for the positive polarity behavior of disjunction is not immediately compatible with the proposal offered in Chierchia 2013 to account for the distribution of NPIs. The com- 
Deriving the positive polarity behavior of plain disjunction

parison is done with Chierchia's account for the simple reason that this is the most recent large scale discussion of the polarity system that is also couched within the grammatical approach to implicature calculation. The reason for the incompatibility is due to the fact that Chierchia does not employ a contradiction-free method of exhaustification, namely one that only takes into account innocently excludable alternatives. In fact, his system for deriving the unacceptability of NPIs in non-DE environments hinges on the contradiction incurred by negating non-innocently excludable alternatives. On the other hand, the analysis employed here to account for the distribution of PPIs hinges on the fact that exhaustification is contradiction-free, for else elements that are PPIs would systematically be predicted to be unavailable in both DE and UE contexts. While the current paper is not the appropriate venue for a deep investigation of these issues, I would like to leave the reader with some semblance of a resolution to this conflict by pointing out that another implicature-based account of NPIs that is also compatible with the present analysis of PPIs can be found in the work of Crnič (2014). Crnič analyzes NPIs as end-of-scale indefinites that obligatorily trigger exhaustification via an even-like operator (as opposed to the Chierchia's approach which takes NPIs to trigger obligatory exhaustification via $\mathcal{E} x h$ ). Connected to this point, it is also worth mentioning the behavior of either or in English, a complex disjunction that does not exhibit PPI behavior (see fn. 6). This is prima facie a problem since as a complex disjunction, either or must trigger obligatory exhaustification, which in turn should result in unacceptability under negation. What seems to be at play is the fact that either can also function as an NPI, with a meaning not much different from that of any:

(41) Mary didn't invite either/any of them.

One possible avenue for future research would be to argue that either or is a polarity sensitive item, but that unlike run of the mill NPIs and PPIs, it does not discriminate between the type of exhaustifier it can associate with; while it obligatorily triggers exhaustification, the exhaustifier can be either $\mathcal{E} x h$, delivering its behavior in UE contexts, or Crnič's NPI exhaustifier, delivering its acceptability in DE environments. In other words, a sentence with either or is ambiguous between an LF with $\mathcal{E} x h$ and an LF with even, the choice being determined by whichever one leads to a non-contradictory meaning in the end. 
Nicolae

\section{References}

Alonso-Ovalle, Luis. 2006. Disjunction in alternative semantics. Amherst, MA: University of Massachusetts at Amherst dissertation.

Alonso-Ovalle, Luis \& Paula Menéndez-Benito. 2010. Modal indefinites. Natural Language Semantics 18(1). 1-31. https://doi.org/10.1007/s11050-0099048-4.

Chierchia, Gennaro. 2004. Scalar implicatures, polarity phenomena, and the syntax/pragmatics interface. In Adriana Belletti (ed.), Structures and Beyond, vol. 3, 39-103. Oxford University Press.

Chierchia, Gennaro. 2006. Broaden your Views: Implicatures of Domain Widening and the 'Logicality' of Language. Linguistic Inquiry 37(4). 535590. https://doi.org/10.1162/ling.2006.37.4.535.

Chierchia, Gennaro. 2013. Logic in Grammar. Oxford University Press. https: //doi.org/10.1093/acprof:oso/9780199697977.001.0001.

Chierchia, Gennaro, Danny Fox \& Benjamin Spector. 2012. Scalar implicatures as a grammatical phenomenon. In Claudia Maienborn, Paul Portner \& Klaus von Heusinger (eds.), Semantics: An International Handbook of Natural Language Meaning, Berlin \& Boston: de Gruyter, vol. 3, 2297-2332. New York, NY: Mouton de Gruyter.

Crnič, Luka. 2014. Non-monotonicity in NPI licensing. Natural Language Semantics 22(2). 169-217. https://doi.org/10.1007/s11050-014-9104-6.

Crnič, Luka, Emmanuel Chemla \& Danny Fox. 2015. Scalar implicatures of embedded disjunction. Natural Language Semantics 23(4). 271-305. https: //doi.org/10.1007/s11050-015-9116-X.

Dalrymple, M., M. Kanazawa, Y. Kim, S. Mchombo \& S. Peters. 1998. Reciprocal expressions and the concept of reciprocity. Linguistics and Philosophy 21(2). 159-210. https://doi.org/10.1023/A:1005330227480.

Fălăuş, Anamaria. 2010. Alternatives as sources of semantic dependency. In Nan Li \& David Lutz (eds.), Semantics and Linguistic Theory (SALT) 20, 406-427. https://doi.org/http://dx.doi.org/10.3765/salt.v2oio.2546.

von Fintel, Kai. 1999. NPI licensing, Strawson-entailment, and context dependency. Journal of Semantics 16(2). 97-148. https://doi.org/10.1093/jos/16. 2.97.

Fox, Danny. 2007. Free Choice Disjunction and the Theory of Scalar Implicatures. In Uli Sauerland \& Penka Stateva (eds.), Presupposition and Implicature in Compositional Semantics, 71-120. New York: Palgrave Macmillan. 
Deriving the positive polarity behavior of plain disjunction

Fox, Danny \& Roni Katzir. 2011. On the characterization of alternatives. Natural Language Semantics 19(1). 87-107. https://doi.org/10.1007/ s11050-010-9065-3.

Fox, Danny \& Benjamin Spector. 2018. Economy and embedded exhaustification. Natural Language Semantics 26(1). https://doi.org/10.1007/s11050017-9139-6.

Gajewski, Jon. 2011. Licensing strong NPIs. Natural Language Semantics 19(2). 109-148. https://doi.org/10.1007/s11050-010-9067-1.

Gazdar, Gerald. 1979. Pragmatics: Implicature, Presupposition, and Logical Form. New York, N.Y.: Academic Press.

Homer, Vincent. 2009. Disruption of NPI licensing: The case of presuppositions. In Tova Friedman \& Satoshi Ito (eds.), Semantics and Linguistic Theory (SALT) 18, 429-446. https://doi.org/http://dx.doi.org/10.3765/ salt.v18io.2483.

Ivlieva, Natalia. 2012. Obligatory implicatures and grammaticality. In Maria Aloni, blah \& blah (eds.), Amsterdam colloquium 18, 381-390. https://doi. org/10.1007/978-3-642-31482-7-39.

Kratzer, Angelika \& Junko Shimoyama. 2002. Indeterminate pronouns: the view from Japanese. In Yukio Otso (ed.), Tokyo Conference on Psycholinguistics, vol. 3, 1-25.

Krifka, Manfred. 1995. The semantics and pragmatics of polarity items. Linguistic Analysis 25. 209-257.

Meyer, Marie-Christine. 2013. Ignorance and grammar. Cambridge, MA: Massachusetts Institute of Technology dissertation.

Nicolae, Andreea C. 2012. Negation-resistant polarity items. In Christopher Piñón (ed.), Empirical Issues in Syntax and Semantics 9, 225-242.

Nicolae, Andreea C. 2016. Simple disjunction PPIs - a case for obligatory epistemic inferences. In Christopher Hammerly \& Brandon Prickett (eds.), North East Linguistic Society (NELS) 46, vol. 3, 49-62.

Nicolae, Andreea C. \& Uli Sauerland. 2016. A contest of strength: or versus either or. In Nadine Bade, Polina Berezovskaya \& Anthea Schüller (eds.), Sinn und Bedeutung 20, 551-568.

Sauerland, Uli. 2004. Scalar implicatures in complex sentences. Linguistics and Philosophy 27(3). 367-391. https://doi.org/10.1023/B:LING.0oooo23378. 71748.db.

Spector, Benjamin. 2006. Aspects de la pragmatique des opérateurs logiques. Paris, France: Université Paris-VII dissertation. 
Spector, Benjamin. 2014. Global positive polarity items and obligatory exhaustivity. Semantics and Pragmatics 7(11). 1-61. https://doi.org/\$10. 3765/sp.7.11\$.

Szabolcsi, Anna. 2004. Positive polarity - negative polarity. Natural Language and Linguistic Theory 22(2). 409-452. https://doi.org/10.1023/B:NALA. ooooo15791.00288.43.

van der Wouden, Ton. 1997. Negative contexts: Collocation, polarity and multiple negation. London: Routledge.

Zimmermann, Ede. 200o. Free choice disjunction and epistemic possibility. Natural Language Semantics 8(4). 255-290. https://doi.org/10.1023/A: 1011255819284.

Andreea C. Nicolae Leibniz-Zentrum Allgemeine Sprachwissenschaft Schützenstraße 18 D-10117 Berlin, Germany nicolae@leibniz-zas.de 